\title{
POR UMA LEITURA DA REALIDADE PRESENTE NA PERSPECTIVA DE MILTON SCHWANTES ${ }^{1}$
}

\section{For a reading of the reality present in Milton Schwantes' perspective}

\author{
Wallace Soares da Cruz ${ }^{2}$
}

\section{Resumo:}

O artigo propõe o resgate de elementos de mediação pastoral/social da teologia de Milton Schwantes para uma leitura da realidade presente. Novos desafios estão emergindo por causa de um inimigo invisível (COVID-19). A prevenção e o combate à doença exigem um distanciamento físico - não social. O sofrimento se agrava à medida que se intensificam o desemprego, a fome, a pauperização das relações, entre outros problemas. Essa realidade sombria solicita por uma leitura bíblica e uma reflexão teológica capazes de situar o sentido do texto bíblico no aqui e agora. No esforço de propor um caminho possível, o artigo o faz em três passos. Primeiro, apresenta a teologia bíblica de Milton Schwantes sob a ótica de outras/os pesquisadoras e pesquisadores. Evidenciando a relevância e a pertinência dos projetos teológicos do autor. Depois, são extraídos alguns elementos de mediação pastoral/social, de textos selecionados, para delinear as propostas desta pesquisa. Por fim, propõe-se uma leitura da realidade presente na perspectiva de Schwantes. Ele produziu uma teologia que enfatiza o valor da vida e posteridade, desafia as instituições religiosas a uma ação pastoral/social junto aos movimentos populares e reivindica que as relações sociais se enriqueçam na partilha, na complementariedade, na luta pela vida e cidadania.

Palavras-chave: Teologia Bíblica; Milton Schwantes; Realidade Presente; Mediação Pastoral/Social.

\section{Abstract:}

The article proposes the rescue of elements of pastoral/social mediation from Milton Schwantes' theology for a reading of the present reality. New challenges are emerging because of an invisible enemy (COVID-19). Preventing and fighting the disease requires physical, not social, distance. Suffering worsens as unemployment, hunger, and the impoverishment of relationships intensify, among others problems. This gloomy reality calls for a biblical reading and a theological reflection capable of placing the meaning of the biblical text in the here and now. In an effort to propose a possible path, the article does so in three steps. First, it presents the biblical theology of Milton Schwantes from the perspective of other researchers. Evidencing the relevance and the pertinence of the author's theological projects.

1 Submetido em: 06.05.2020. Aceito em: 13.08.2020.

2 Graduação em Administração de Empresas pela Fundação de Assistência e Educação, FAESA, ES, e em Teologia pela Faculdade Unida de Vitória, ES. Especialização em Gestão e Docência no Ensino Superior. Mestrando em Ciências das Religiões pela Faculdade Unida de Vitória, ES. Contato: soares.ensino@gmail.com.

Protestantismo em Revista | São Leopoldo | v. 46, n. 01 | p. 34-49| Jan./jun. 2020

Disponível em: <http://periodicos.est.edu.br/index.php/nepp> 
Then, some elements of pastoral/social mediation are extracted from selected texts to outline the proposals of this research. Finally, we propose a reading of the reality present in Schwantes' perspective. He produced a theology that emphasizes the value of life and posterity, challenges religious institutions to pastoral/social action with popular movements and claims that social relations are enriched is sharing, in complementarity, in the struggle for life and citizenship.

Keywords: Biblical Theology; Milton Schwantes; Present Reality; Pastoral/Social Mediation.

\section{Introdução}

A despeito dos avanços das ciências e do progresso alcançado pela sociedade, o ser humano não deixou de experimentar os diferentes tipos de sofrimento. Ao contrário, na atualidade emergem novas formas de sofrimento para as quais as ciências ainda não encontraram soluções plausíveis. A pauperização das relações, da experiência do vazio existencial, da busca pelo suicídio e, simultaneamente, uma procura pelo sagrado cada vez mais independente das instituições religiosas, ${ }^{3}$ são algumas das marcas que evidenciam esse dilema paradoxal. Por conseguinte, cada vez mais as pessoas estão se isolando em relações virtuais nas redes sociais. ${ }^{4}$

A situação se agrava ainda mais no atual contexto de distanciamento físico ${ }^{5}$ - não social - em que as pessoas estão se submetendo em virtude da pandemia do novo coronavírus (COVID-19) ${ }^{6}$. O afastamento visa evitar a evolução do vírus. No Brasil, sobretudo nas redes sociais, as pessoas estão se digladiando entre si com opiniões contra ou a favor da reclusão. A rotina da maioria das pessoas foi alterada. O desemprego, a fome, o medo, a violência, entre tantas coisas, entenebrecem o sofrimento de um povo. A realidade difícil torna-se ainda mais assombrosa. Essa realidade solicita por uma leitura bíblica e uma reflexão teológica capazes de situar o sentido do texto bíblico no aqui e agora.

3 Entre muitas possibilidades, essa busca autônoma pelo sagrado pode exprimir o desejo pela superação do sofrimento causado por algumas instituições eclesiais, muitas vezes, adoecedoras e não mais terapêuticas. Pode, também, ser fruto do fenômeno da privatização da religião no qual o indivíduo acaba cristalizando um individualismo contemporâneo. Pois, há nele um desejo de autonomia em relação às instituições religiosas e, por isso, se apropriam de diferentes elementos religiosos configurando sua própria religião. Cf. BERGER, Peter L. O dossel sagrado: elementos para uma teoria sociológica da religião. São Paulo: Paulinas, 1985. p. 149.

4 Castells assenta que não se trata apenas de uma virtualidade, mas de uma construção de uma "realidade virtual". CASTELLS, Manuel. A sociedade em rede. São Paulo: Paz e Terra, 2005. p. 459.

5 Considerando o desafio teológico que a realidade presente nos impõe, este artigo defende o uso da expressão distanciamento físico e não social. Pois, a interação social mantém firme o relacionamento entre os indivíduos, ao menos o pressupõe. Tão logo, a expressão pretende remeter à memória e defesa dos direitos dos grupos mais desfavorecidos. A despeito de se afirmar uma tendência ao isolamento em relações virtuais nas redes sociais, a expressão deve ser compreendida aqui como um desafio lançado para superação desta e de outras posturas individualizantes que deterioraram as relações humanas.

6 O Ministério da Saúde informa que é uma doença causada pelo coronavírus SARS-CoV-2, que apresenta um quadro clínico que varia de infeç̧ões assintomáticas a quadros respiratórios graves. O novo agente do coronavírus foi descoberto em 31.12.2019 após casos registrados na China. Provoca a doença chamada de coronavírus (COVID-19). Para obter mais detalhes, ver: <https://coronavirus.saude.gov.br/sobre-adoenca\#o-que-e-covid>. Acesso em 17 abr. 2020.

Protestantismo em Revista | São Leopoldo | v. 46, n. 01 | p. 34-49| Jan./jun. 2020

Disponível em: <http://periodicos.est.edu.br/index.php/nepp> 
Este artigo, portanto, pretende resgatar os elementos de mediação pastoral/social da teologia bíblica de Milton Schwantes para uma leitura da realidade presente. Para ele, a Bíblia é uma palavra que reinterpreta a vida. Ao assumir a práxis na perspectiva do oprimido sua teologia redunda em práticas libertadoras. ${ }^{7}$ Este exímio autor faleceu no ano de $2012 \mathrm{e}$ deixou inúmeras contribuições e um legado que não pode ser esquecido. ${ }^{8}$ Este artigo não aponta para uma solução ao problema do sofrimento das pessoas. Mas levanta a seguinte questão: o que se pode fazer neste tempo? Sugere, como caminho possível, um pensar teológico a serviço da vida e contextualização da mensagem bíblica. O interesse não é produzir um trabalho exaustivo e conclusivo, mas lançar estímulos e desafios para uma ética do cuidado eficiente a partir de alguns elementos de mediação pastoral/social extraídos da teologia de Schwantes.

O artigo faz isso em três passos. Primeiro, esboça-se a opinião de alguns pesquisadores/as a respeito de Milton Schwantes e sua teologia. O objetivo corolário é responder a seguinte questão: o que dizem os/as teólogos/as e os/as biblistas sobre a pessoa e a teologia de Schwantes? Reconhecem-se, sobretudo, os limites impostos por um artigo, isto é, não se tem espaço para uma descrição pormenorizada. O tema é amplo e complexo. Por isso, foram selecionados apenas alguns textos. Portanto, não se trata de legitimar um texto em detrimento de outros, mas de adequar-se a esses limites.

Depois, analisam-se alguns textos de Schwantes buscando extrair alguns elementos de mediação pastoral/social de uma leitura bíblica em benefício do oprimido. O objetivo é deixar ecoar a voz do autor, através de seus escritos, e mostrar que ela não está silenciada na atualidade. Isto é, os princípios teológicos de Schwantes podem ser rememorados e aplicados à realidade presente. Por último, propõe uma leitura da realidade presente na perspectiva de Schwantes como reflexão plausível para os novos desafios que surgem. Em Schwantes, Deus é apresentado como um deus que age e o Messias é pobre e tem preferência pelos oprimidos. Entretanto, esta teologia tem seu lugar no serviço das instituições religiosas junto aos movimentos populares, enraizada na ação pastoral/social. Da mesma forma, no dia a dia, a Bíblia é uma companhia indispensável.

Compreende-se que a teologia de Schwantes enfatiza o valor da vida e posteridade. Ela desafia as instituições religiosas a uma ação pastoral/social junto aos movimentos populares. Reivindica que as relações sociais se enriqueçam na partilha, na complementariedade, na luta pela vida e cidadania. Portanto, a voz de Milton Schwantes torna-se indispensável para uma leitura da realidade presente.

\section{Alguns traços de repercussões das contribuições de Milton Schwantes}

No ano de 1983, em Belo Horizonte, durante uma reunião organizada pelo CEBI, Milton Schwantes pegou um graveto, segurou-o em cima de um fogo que estava aceso no centro da assembleia e disse: "Tudo que fizermos com a Bíblia para a formação: pesquisa, estudo, línguas, cursos, projetos, aprofundamento, comentários, se não estiver a serviços dos

7 SCHWANTES, Milton. O êxodo como evento exemplar. Estudos Bíblicos, Petrópolis, v. 16, p. 9-18, 1988a. p. 14-18.

8 Para um perfil biográfico de Milton Schwantes, ver DREHER, C. A. Milton Schwantes: um perfil biográfico. In: DREHER, C. A. et. Al. (Org.). Profecia e Esperança: um tributo a Milton Schwantes. São Leopoldo: Oikos, 2006. p. 11-23.

Protestantismo em Revista | São Leopoldo | v. 46, n. 01 | p. 34-49| Jan./jun. 2020

Disponível em: <http://periodicos.est.edu.br/index.php/nepp> 
grupos de base, onde a palavra de Deus entra na vida" - então, ele deixou o graveto cair no fogo - "que seja queimado e esquecido" . Schwantes tinha um jeito singular de ler e interpretar a Bíblia. Sua leitura e interpretação legitimavam e defendiam a vida e se preocupava tanto com os grandes problemas da humanidade quanto com os pequenos assuntos do dia a dia. ${ }^{10}$

A despeito de seu falecimento no ano de 2012, Schwantes deixou uma vasta produção acadêmica - centenas de artigos e dezenas de livros - suas contribuições ultrapassaram as fronteiras internacionais. ${ }^{11}$ Suas obras são perpassadas por reflexões ecumênicas e de ênfases sociais e políticas. Elas apresentam uma teologia arraigada no tempo e produzida em resposta a ele. Para exemplificar, segue um recorte de um texto publicado no final da década de 1980:

As igrejas como que coloriram [...] Não viam o que estavam vendo. Os índios foram massacrados. Foram vitimados por um monstruoso genocídio. Os escravos negros foram esgotados em suas forças. Foram açoitados, difamados pela cor. Operárias e operários estão sendo submetidos à crescente exploração. $E$ as igrejas quase que se apartam desta violência toda, desta brutalidade monstruosa, como se não fosse de sua alçada, como se não dissesse respeito a seu ministério. ${ }^{12}$

O exemplo mostra que a crítica social está bem delineada e compreensível, no entanto, a expressão "como que coloriram" comunica uma falha das igrejas naquela época, no entendimento do autor. Mas, essas questões serão aprofundadas mais a frente. Segue-se aqui com os apontamentos apresentados por vários pesquisadores e pesquisadoras sobre a teologia de Schwantes.

Ivone Reimer e Haroldo Reimer destacam uma contribuição ímpar da tese de Milton Schwantes para as universidades e movimentos em nível internacional. Trata-se de um profundo sentimento de misericórdia que "põe Deus em movimento para transformar a situação de miséria e sofrimento destas pessoas na restauração do direito dos pobres" ${ }^{13}$. Para eles, a misericórdia é gestada no útero como uma "emoção profunda que, nas situações injustas e sofridas, leva a intervir em favor da vida"14. Isto é, misericórdia - sentimento-ação - perpassada pela ética do cuidado. ${ }^{15}$ Neste sentido, a manifestação da misericórdia está ligada a contextos de sofrimento. Sendo assim, uma situação de empobrecimento, abandono e doenças fazia o povo clamar. Estes clamores "dão luz a misericórdia de Deus em ações interventoras e transformadoras"16.

9 MERSTERS, Carlos. Milton, nosso mestre. In: PEREIRA, Nancy Cardoso (Org.). Milton Schwantes: escritos de história e paixão. São Leopoldo: CEBI, 2012. p. 11. Ver também: WITT, Hans de. "It Should Be Burned And Forgotten!" Latin American Liberation Hermeneutics through the Eyes of Another. In: BOTTA, Alejandro F.; ANDIÑACH, Pablo R. The Bible and the Hermeneutics of Liberation. Atlanta: Society of Biblical Literature, 2009. p. 39.

10 MERSTERS, 2012, p. 7-9.

11 DREHER, 2006, p. 11-23.

12 SCHWANTES, Milton. Toda criação geme e suporta angústias. Tempo e Presença, Rio de Janeiro, n. 246, p. 2930, 1989a. p. 30.

13 REIMER, Ivoni Richter; REIMER, Haroldo. Misericórdia quero! Uma ética do cuidado a partir das entranhas. Estudos Bíblicos, Petrópolis, v. 29, n. 114, p. 27-37, 2012. p. 28.

14 REIMER; REIMER, 2012, p. 28.

15 REIMER; REIMER, 2012, p. 28.

16 REIMER; REIMER, 2012, p. 30.

Protestantismo em Revista | São Leopoldo | v. 46, n. 01 | p. 34-49| Jan./jun. 2020

Disponível em: <http://periodicos.est.edu.br/index.php/nepp> 
Marcelo Barros fez uma releitura do salmo 121, à luz de um estudo de Milton Schwantes, refletindo-o a partir da vida. Ele ressalta que, na perspectiva de Schwantes, o próprio Deus é sombra que protege as pessoas dos riscos da insolação durante o dia e de fluidos negativos da lua à noite. Isto é, "Deus faz isso, tornando o sol e a lua nossos aliados na terra. Isso nos coloca na sensibilidade ecológica atual em que os elementos do céu e da terra se unem como sinais e instrumentos divinos da nossa caminhada" ${ }^{17}$. Neste salmo, o próprio Deus tornou-se sombra para proteger o seu povo e "todo mundo sabe o que significa uma boa sombra no calorão dos nossos sertões, caatingas ou cerrados" ${ }^{18}$.

Mesmo no diálogo com as pesquisas no campo da arqueologia é possível perceber os rastros da teologia Schwantes. José Ademar Kaefer informa que a arqueologia se tornou indispensável para o exegeta. No entanto, a despeito de sua relevância, ela não substitui o texto. ${ }^{19}$ Isso porque, para Schwantes - nas palavras de Kaefer - a arqueologia tem "dificuldades para encontrar artigos, objetos que falam do cotidiano da vida do povo pobre [...] É mais fácil [...] encontrar grandes construções: palácios, templos, muralhas [...] que falam da vida dos reis" ${ }^{20}$. Neste sentido, as descobertas arqueológicas não impressionam Schwantes, mas levantam questões teológicas, tais como: "as vítimas, onde estão? Onde estão os jovens que morreram nas guerras para garantir os sonhos megalomaníacos dos reis? Onde está o povo que teve que pagar tributos abusivos para manter as guerras?" 21 , entre outras perguntas.

Para Tércio Machado Siqueira, como teólogo, Schwantes abriu "caminhos novos que dificilmente se tornarão envelhecidos, dado ao vigor, o arrojo e coerência de seus projetos"22. Como pastor e professor, "ele converteu a busca da teologia ideal, acadêmica, em ações práticas a favor dos necessitados, e do bem-estar do povo latino-americano [...] a esse povo, Schwantes se colocou, plenamente, disponível para executar o seu dom de intérprete da Bíblia"23. Além disso, Tércio menciona outras grandes contribuições de Schwantes, por exemplo, a criação de duas revistas voltadas para estudantes da Bíblia: Estudos Bíblicos e Revista de Interpretação Bíblica Latino-Americana (RIBLA). O objetivo, segundo Tércio, era difundir o material bíblico produzido na América Latina e facilitar a pesquisa. ${ }^{24}$

Cláudio de Oliveira Ribeiro escreveu um ensaio sobre os aspectos ecumênicos da teologia de Schwantes considerando que "a vida em comunidade [...] é geradora de formas de superação das crises sociais" ${ }^{25}$. O autor reforça a necessidade de que sejam laboradas futuras pesquisas sobre o pensamento teológico de Schwantes. Sobretudo, sobre os aspectos ecumênicos e de ênfases social e política. Cláudio Ribeiro compreende que tais aspectos foram

17 BARROS, Marcelo. Salmo das travessias - conversa com Milton Schwantes sobre o salmo 121. Estudos Bíblicos, Petrópolis, v. 29, n. 114, p. 19-26, 2012. p. 25.

18 BARROS, 2012, p. 25.

19 KAEFER, José Ademar. A estela de Dã. Caminhando, São Bernardo do Campo, v. 17, n. 2, p. 33-46, 2012. p. 34.

20 KAEFER, 2012, p. 34.

21 KAEFER, 2012, p. 45.

22 SIQUEIRA, Tércio Machado. A Torá: uma leitura inovadora. Caminhando, Petrópolis, v. 17, n. 2, p. 21-31, 2012. p. 21.

23 SIQUEIRA, 2012, p. 22.

24 SIQUEIRA, 2012, p. 22.

25 RIBEIRO, Cláudio de Oliveira. "O olhar de quem sabe amar": aspectos da teologia ecumênica e sociopolítica de Milton Schwantes. Caminhando, São Bernardo do Campo, v. 17, n. 2, p. 95-106, 2012. p. 105.

Protestantismo em Revista | São Leopoldo | v. 46, n. 01 | p. 34-49| Jan./jun. 2020

Disponível em: <http://periodicos.est.edu.br/index.php/nepp> 
articulados com os esforços exegéticos que Schwantes realizou ao longo de sua trajetória como pesquisador. Por isso, o legado de Schwantes pode ser mais bem mensurado por meio dessas pesquisas. ${ }^{26} \mathrm{O}$ desafio, portanto, fora lançado para esta geração.

Ao perscrutar a exegese latino-americana, Hans de Wit elenca alguns aspectos relevantes dos trabalhos de Schwantes. Segundo ele, a importância dada às perícopes no Pentateuco e a tese da autoria do texto bíblico, atribuída às camadas populares de Israel, representa uma das contribuições mais relevantes deixadas pelo biblista. ${ }^{27}$ Pois, na linha de uma leitura materialista da Bíblia, Schwantes apresenta a sociedade israelita em uma constante relação de conflito entre campo e cidade. Esta oposição tem também sua expressão literária. Isto é, o campo é representado pelas perícopes - que preservam a memória popular e campesina - e a cidade, por sua vez, pelos grandes blocos literários - elaborados, em geral, no contexto do templo e/ou do Estado. ${ }^{28}$ Schwantes está mais orientado sociologicamente. Em suas obras não se enfatiza muito a estrutura linguística dos textos e nem suas peculiaridades literárias. O maior interesse está, portanto, na referência histórica. Neste sentido, a exegese de Schwantes consiste em dois passos metodológicos: leitura históricosociológica do texto e atualização/aplicação. ${ }^{29}$

A despeito do interesse pela referência histórica, o corpus literário do exegeta também espelha anúncios de esperança para a população pobre e desassistida. É o que afirma Suely Xavier dos Santos em seu artigo sobre o messianismo em Milton Schwantes. ${ }^{30}$ Ela postula que Schwantes expandiu a discussão sobre o messianismo bíblico, desenvolvendo "uma teologia que sistematizou o pensamento sobre o assunto de tal forma que a compreensão do Novo Testamento ficou clara por meio de sua proposta" ${ }^{31}$. 0 aspecto central dessa teologia é o anúncio de um "messias desvinculado das esferas de poder" ${ }^{32}$ e, nesse sentido, vai tomando forma de cruz. Segundo a autora, foi assim que Schwantes viveu e desenvolveu um pensamento messiânico a partir da realidade do povo pobre e excluído, "mas que encontra seu lugar na história a partir da cruz"33.

Muitos textos não foram inseridos nesta discussão por questões inerentes aos limites que um artigo científico impõe. No entanto, os exemplos aqui mencionados desvelam o caráter, a importância e a atualidade de uma teologia que não pode ser "queimada e esquecida". Trata-se de mulheres e homens influenciadas/os, direta ou indiretamente, pela vida e obra de Milton Schwantes. Na seção seguinte, será feita uma breve análise sobre alguns textos de Schwantes. O objetivo corolário é extrair o seu testemunho à luz de seus próprios textos. Isto é, já foi manifestada a opinião sobre ele, agora, chegou o momento de ouvir o que ele continua dizendo por meio de seus escritos.

26 RIBEIRO, 2012, p. 106.

27 WIT, Hans de. En la dispersión el texto es patria: introducción a la hermenéutica clásica, moderna e pósmoderna. San José (Costa Rica): Universidad Bíblica Latino Americana, 2002. p. 255-258.

28 WIT, 2002, p. 255.

29 WIT, 2002, p. 256-257.

30 SANTOS, Suely Xavier. Milton Schwantes: a messianidade vai tomando forma de cruz! Caminhando, São Bernardo do Campo, v. 17, n. 2, p. 47-54, 2012. p. 47-54.

31 SANTOS, 2012, p. 53.

32 SANTOS, 2012, p. 53.

SANTOS, 2012, p. 53.

Protestantismo em Revista | São Leopoldo | v. 46, n. 01 | p. 34-49| Jan./jun. 2020

Disponível em: <http://periodicos.est.edu.br/index.php/nepp> 


\section{Milton Schwantes: uma voz que ainda ecoa...}

Após relatar alguns traços da repercussão da teologia de Schwantes, pretende-se agora extrair de seus textos alguns elementos de mediação pastoral/social que evidenciam o caráter transformador de sua interpretação bíblica. O objetivo é situar a teologia de Milton Schwantes como "uma voz que ainda ecoa...". Parte-se do pressuposto de que por meio de seus escritos sua voz ainda reverbera no presente. A reticência, por sua vez, indica a possibilidade de continuidade de seus projetos teológicos. ${ }^{34}$

A tese de Milton Schwantes intitulada "O direito dos Pobres"35 sistematiza os conceitos utilizados para caracterizar os pobres na Lei e nos Profetas. Trata-se de uma obra densa que, em suma, assenta que o lugar dos pobres não é a periferia, mas que eles são praticamente idênticos ao povo de Deus. Deus, portanto, é um deus que se volta para os que sofrem. ${ }^{36}$ A centralidade da tese está no grupo dos socialmente fracos do antigo Israel e o conteúdo não deixa dúvidas de que "a dedicação às pessoas necessitadas pertence ao centro do agir divino e da prática de seu povo" ${ }^{37}$.

Não é incomum entre os cristãos, sobretudo nos meios populares, que o uso da expressão "povo de Deus" faça alusão à igreja. Como já foi dito, Schwantes assenta que a dedicação às pessoas que sofrem também está ligada à prática do povo de Deus. Essa afirmação remete a uma crítica que ele faz ao profeta Natã. Para Schwantes, ele é um profeta "bajulador" e aliado à corte real e seus interesses. ${ }^{38}$ Ele afirma que Natã não cumpre seu papel profético. Mas, faz opção à manutenção do reinado de Davi. Por isso, os interesses de uma igreja profética deveriam seguir na contra mão de seu exemplo. Uma igreja profética não está ligada aos interesses reais, mas se liga aos colonos de Judá, isto é, ao povo oprimido. Para ele, "a igreja profética é um ensaio urgente e necessário em nossa situação" 39 .

Schwantes situa o oprimido como um novo sujeito histórico. No contexto latinoamericano, os oprimidos se apropriam da memória bíblica e recriam sua reserva de sentido "como denúncia conscientizadora da opressão e anúncio animador da libertação" 40 . Essa apropriação é um dado e não conjectura. Por isso, deve-se "efetivar uma leitura bíblica encarnada no clamor atual dos povos oprimidos" ${ }^{41}$. Para ele, as questões concretas, materiais

34 O contato com as obras de Milton Schwantes marcou profundamente minha trajetória acadêmica. Durante um momento decisivo, marcado pelo desemprego e dificuldades financeiras, decidi estudar Teologia. Na graduação obtive uma bolsa de 50\%, exigindo muito esforço e disciplina para trabalhar (mesmo que informal) e estudar. Realidade comumente experimentada por muitos estudantes brasileiros. Em 2019, fui contemplado com uma bolsa integral no Programa de Mestrado em Ciências das Religiões da Faculdade Unida de Vitória, no Espírito Santo. Não hesitei em pesquisar o corpus literário de Schwantes. Sua maneira de ler e interpretar a Bíblia me fascina. Portanto, a voz deste autor reverbera através de seus textos. Ela pode ganhar novas tonalidades por meio daqueles que desejam dar continuidade aos seus projetos.

35 Em alemão a obra é intitulada "Das Recht der Armen". No Brasil, foi publicada na língua portuguesa pelas editoras Oikos e Editeo, em 2013.

36 SCHWANTES, Milton. O direito dos pobres. São Leopoldo: Oikos; São Bernardo do Campo: Editeo, 2013. p. 329-333.

37 SCHWANTES, 2013, p. 333.

38 SCHWANTES, Milton. Natã precisa de Davi - na esperança da igreja profética. Estudos Teológicos, São Leopoldo, ano 18, n. 3, p. 99-118, 1978. p. 116.

39 SCHWANTES, 1978, p. 118.

40 SCHWANTES, Milton. Interpretação de Gn 12-25, no contexto da elaboração de uma hermenêutica do Pentateuco. Estudos Bíblicos, Petrópolis, p. 31-49, 1984a. p. 31.

41 SCHWANTES, 1984a, p. 31.

Protestantismo em Revista | São Leopoldo | v. 46, n. 01 | p. 34-49| Jan./jun. 2020

Disponível em: <http://periodicos.est.edu.br/index.php/nepp> 
e políticas devem ser a porta de entrada para o texto bíblico. Pois, "com isso a interpretação permanecerá no nível do real, simplificando a compreensão do texto antigo e mantendo sua avaliação próxima a nossa realidade" ${ }^{\prime 2}$. Neste sentido, quando se leva em conta as questões concretas, a interpretação cresce em relevância e a aprofunda sua dimensão de encarnação. ${ }^{43}$

O povo sofrido são os atores na teologia de Schwantes. De sorte que "o paradigma para a vida é a periferia [...]. O sistema de espoliação capitalista estoura na vila e nas periferias" ${ }^{\prime 4}$. Para ele, "o movimento social é a própria matriz na literatura profética" 45 . Por isso, uma igreja profética deveria considerar dois elementos fundamentais presentes na profecia bíblica - denuncia e ameaça. Para Schwantes, "a origem da denúncia [...] está no movimento social. [...] a denúncia brotou do chão do movimento social. Nele surge e a ele reforça" 46 . A ameaça, por sua vez, "atinge não só as pessoas, mas principalmente as instituições" 47 . Portanto, "impulsos decisivos para a nova igreja [...] provêm da inserção consciente e consequente das igrejas nos movimentos populares" ${ }^{48}$.

Estas são, pois, características essenciais para o modelo de igreja tão pretendido por Schwantes. Isto é, uma igreja convertida aos pobres, ${ }^{49}$ com perfil profundamente ecumênico $^{50}$ e que privilegie uma "interação entre agenda do mundo e agenda de igreja" 51 . De modo que as camadas populares tenham "acesso aos órgãos de decisão das igrejas" 52 . Neste sentido, Schwantes desafia as estruturas das organizações eclesiásticas consolidadas a reinventar-se à luz da redescoberta da Bíblia na América Latina. Ou seja, "a nova leitura bíblica latinoamericana está sediada neste processo, em que igrejas e cristãos são solidários com operários e camponeses em sua luta pela libertação, em que o próprio povo empobrecido assume igreja" ${ }^{53}$. Configurando, assim, uma igreja de rosto popular, onde a miséria das pessoas deverá ter espaço nela. ${ }^{54}$

Entretanto, "esta releitura da Escritura em meio aos pobres é tarefa ecumênica" 55 , assenta Schwantes. Sua crítica é contra certa apropriação do texto bíblico, de modo que "cada igreja foi tendo 'sua Bíblia', seu jeito de interpretar"56. Acentuando, desta forma, o distanciamento e a desunião entre igrejas e, consequentemente, "a leitura bíblica foi sendo

42 SCHWANTES, 1984a, p. 40.

43 SCHWANTES, 1984a, p. 48.

44 SCHWANTES, Milton. "Da boca dos pequeninos..." - enfoques antropológicos. Estudos Teológicos, São Leopoldo, ano 24, n. 2, p. 148-160, 1984b. p. 160.

45 SCHWANTES, Milton. Profecia e organização - Anotações à luz de um texto (Am 2,6-16). Estudos Bíblicos, Petrópolis, n. 5, p. 26-39, 1985. p. 38.

46 SCHWANTES, 1985, p. 38.

47 SCHWANTES, 1985, p. 38.

48 SCHWANTES, Milton. Teologia Bíblica junto ao povo - anotações preliminares. Estudos de Religião, São Bernardo do Campo, n. 3, p. 43-56, 1987a. p. 46

49 SCHWANTES, Milton. Plantarei o meu povo na terra que Ihes dei. Revista Eclesiástica Brasileira (REB), Petrópolis, v. 52, fasc. 206, p. 424-428, 1992. p. 426.

50 Para Schwantes, é pela diferença que a gente se completa e, nesta lógica, o ecumenismo faz bem às igrejas. Cf. SCHWANTES, 1992, p. 424.

51 SCHWANTES, 1984b, p. 148.

52 SCHWANTES, 1987 a, p. 47.

53 SCHWANTES, 1987a, p. 47.

54 SCHWANTES, Milton. A herança de Javé - meditando o Salmo 127. Estudos Teológicos, ano 27, n. 2, p. 175180, 1987b. p. 180.

55 SCHWANTES, Milton. Caminhos da teologia bíblica. Estudos Bíblicos, Petrópolis, n. 24, p. 9-19, 1989 c. p. 11.

56 SCHWANTES, 1989c, p. 11.

Protestantismo em Revista | São Leopoldo | v. 46, n. 01 | p. 34-49| Jan./jun. 2020

Disponível em: <http://periodicos.est.edu.br/index.php/nepp> 
incorporada à desunião" ${ }^{57}$. Não obstante, Schwantes enfatiza que a experiência ecumênica traz novos desafios, pois, "o ecumenismo nos convida a entender as diferenças como possíveis complementações, não como motivos de separatismos" ${ }^{18}$. As diferenças, portanto, existem, mas não devem estar em primeiro plano. Pois, "o grito dos empobrecidos é um grito ecumênico [...] a Bíblia lida pelos pobres e na solidariedade com eles, já não pode querer recorrer às tradições de uma só igreja" ${ }^{\prime 2}$. Neste sentido, a realidade presente evoca a ecumenicidade.

Nesta lógica, a igreja deve assumir uma atitude profético-sócio-ecumênica. De maneira que "a função profética da Igreja é a de ir às raízes do testemunho escriturístico [...] profecia está correlacionada à fidelidade à palavra escrita" ${ }^{60}$. Ela não despreza as questões sociais emergentes, pois, "a profecia evoca a pequenez" ${ }^{\prime 1}$. É a voz dos empobrecidos e estes "reivindicam uma interpretação que parta do concreto e do social, das dores e utopias da gente latino-americana" ${ }^{62}$. O próprio conteúdo da profecia traz encravado o contexto. ${ }^{63}$ Por isso, à medida que o clamor dos empobrecidos é ecumênico, na mesma intensidade as igrejas são desafiadas a romper com os separatismos em benefício dos espoliados. Para Schwantes, "a junção das diferentes injustiças sofridas por diferentes pessoas cria organização entre os implicados. Portanto, a existência de uma listagem de sofrimentos pressupõe a existência de uma organização de sofredores e injustiçados" ${ }^{\prime \prime 4}$. Neste sentido, uma atitude profético-sócioecumênica pressupõe a denúncia e ameaça das igrejas proféticas em relação às estruturas opressoras vigentes. ${ }^{65}$

Para Schwantes, teologia bíblica é feita junto com e pelo povo. As perguntas são feitas a partir da concretude da vida do oprimido, isto é, daqueles que sofrem. Pois, para ele, "há indícios múltiplos que dão sustentação à possibilidade de que a Escritura tem seu lugar vivencial na periferia"66. Segundo ele, ela nasce na tradição, no contar e recontar e "neste processo de rememorização a cena adquire coesão. É a memória - memória popular e campesina - que consolida o texto" ${ }^{67}$. Portanto, "a escritura é literatura popular e campesina, particularmente fomentada pelos setores mais empobrecidos. Para uma 'teologia bíblica junto ao povo' esta possibilidade é de uma relevância pastoral inusitada" 68 .

A exegese bíblica proposta por Schwantes pretende resgatar o sentido profético do texto bíblico e, a partir daí, construir uma teologia bíblica junto ao povo. Hans de Wit classificou sua exegese em dois passos metodológicos: leitura histórico-sociológica do texto e atualização/aplicação. ${ }^{69}$ Semelhante à profecia, Schwantes assenta que "exegese precisa ajudar a virar, a revirar as ordens estabelecidas, as que criam pobres [...] Exegese que repete

57 SCHWANTES, 1989c, p. 11.

58 SCHWANTES, 1989c, p. 11.

59 SCHWANTES, 1989c, p. 11.

60 SCHWANTES, Milton. Bíblia e Lutero. Caminhando, ano 2, v. 2, p. 32-34, 1984c. p. 33.

61 SCHWANTES, Milton. Jacó é pequeno - visões em Amós 7-9. Revista de Interpretação Bíblica LatinoAmericana, Petrópolis, v. 1, n. 2, p. 81-92, 1988b. p. 84.

62 SCHWANTES, 1988 b, p. 81.

63 SCHWANTES, 1985, p. 27.

64 SCHWANTES, 1985, p. 33.

65 SCHWANTES, 1985, p. 26-39.

66 SCHWANTES, 1987a, p. 54.

67 SCHWANTES, 1987a, p. 55.

68 SCHWANTES, 1987a, p. 55.

69 WIT, 2002, p. 256-257.

Protestantismo em Revista | São Leopoldo | v. 46, n. 01 | p. 34-49| Jan./jun. 2020

Disponível em: <http://periodicos.est.edu.br/index.php/nepp> 
se atola"70. Em outras palavras, a profecia é criativa e revolucionária. ${ }^{71}$ Por isso, para ele, "ao partir do concreto, a exegese bíblica, de início, acontece no contexto da pastoral"72. Em termos metodológicos, ainda que seja imprescindível "observar as estruturas de linguagem, que servem de condutores dos conteúdos destes textos, sejam eles unidades menores ou amplas composições literárias, esta linguagem indubitavelmente está assentada em experiências históricas" ${ }^{\prime 3}$. Destarte, na perspectiva de Schwantes, a análise estrutural é secundária. ${ }^{74}$ Assim, ele pretende localizar as experiências de vida inscritas nas narrativas bíblicas. ${ }^{75}$

A vida é um elemento central na teologia de Schwantes e sua continuidade está implícita. Não basta apenas viver bem, mas deve-se garantir a posteridade. Para ele,

A defesa da vida é esta gente nova [...] é ela que sustenta o direito dos injustiçados [...] ela é a mediação da presença e gratuidade de Javé. A partir daí resplandecem, com intensidade ainda maior, [...] que as casas bem construídas e as cidades bem guarnecidas nada valem se não tiverem em mente a 'herança', filhas e filhos, a gente moça. Em si, casas e instituições não fazem sentido. ${ }^{76}$

A defesa do salmo 127, no entendimento de Schwantes, deixa um desafio para o trabalho pastoral das igrejas. Em suas palavras:

O coração deste salmo bate por pessoas, pela gente nova. Nelas deposita seu entusiasmo. São herança de Javé. Com isso, está colocado um constante desafio para o trabalho pastoral. Ele é um serviço. Um serviço aos que buscam aprofundar sua fé. Um serviço às comunidades inseridas neste país dolorido. Gente é herança que Javé confia à igreja. As alegrias e as misérias das pessoas terão que ter espaço privilegiado nessa instituição. Corremos o risco de privilegiar a "casa" e a "cidade", os edifícios e as instituições. Para estas coisas também poderá haver espaço. São instrumentos de serviço. Nisso consiste sua importância relativa. É relativa ao serviço, cujo conteúdo são pessoas. ${ }^{77}$

Os escritos de Milton Schwantes são perpassados por uma teologia em defesa da vida. O oprimido é o sujeito histórico que se apropria do texto bíblico e recria sua reserva de sentido. A partir da realidade concreta e de seu sofrimento, ele denuncia a opressão e anima a esperança para a libertação. As igrejas, portanto, devem se inserir nos movimentos populares e priorizar a preservação da vida e sua posteridade. São desafiadas a romper com separatismos, conviver com as diferenças e inserir em sua agenda a realidade sofrida das

70 SCHWANTES, Milton. Javé abrigou: anotações teológicas à luz do livro de Sofonias. Estudos de Religião, São Bernardo do Campo, n. 13, p. 25-44, 1997. p. 44.

71 Nas palavras de Schwantes: "a teologia bíblica junto ao povo, para nós, tem contornos revolucionários". Cf. SCHWANTES, 1987a, p. 44.

72 SCHWANTES, 1984a, p. 40.

73 SCHWANTES, Milton. "Não estendas tua mão contra o menino" (Observações sobre Genesis 21 e 22). Revista de Interpretação Bíblica Latino-Americana, Petrópolis, v. 10, p. 24-39, 1991. p. 28.

74 José Severino Croatto, por exemplo, entende a análise estrutural importante para a exegese bíblica ou de qualquer outro texto. Pois, para ele, ao identificar a estrutura de um texto, sua mensagem pode ser descodificada. Cf. CROATTO, José Severino. Hermenêutica bíblica: para uma teoria da leitura como produção de significado. São Leopoldo: Sinodal; São Paulo: Paulinas, 1986. p. 18.

75 SCHWANTES, 1991, p. 27.

76 SCHWANTES, 1987b. p. 179.

77 SCHWANTES, 1987b, p. 180.

Protestantismo em Revista | São Leopoldo | v. 46, n. 01 | p. 34-49| Jan./jun. 2020

Disponível em: <http://periodicos.est.edu.br/index.php/nepp> 
pessoas. Em tempos sombrios, marcados por sofrimento e distanciamento, a teologia de Schwantes se mostra indispensável. Sobretudo, os seus aspectos de mediação pastoral/social.

\section{Por uma leitura da realidade presente}

$\mathrm{Na}$ introdução deste artigo foi feito um breve relato sobre os novos desafios que emergem em virtude de um inimigo invisível - COVID-19. Fala-se, portanto de um distanciamento social como medida preventiva à propagação do vírus. Neste artigo optou-se pela expressão distanciamento físico. O teor da escolha é teológico, indicando que se deve estar fisicamente isolado, mas socialmente à disposição uns aos outros - enquanto perdurar o período de quarentena. Entretanto, não é o foco desta pesquisa discorrer sobre essa situação. Mas, refletir teologicamente sobre os desafios que se impõem nestes dias. São tempos sombrios e de sofrimento que clamam por uma leitura da realidade presente consoante com a teologia de Milton Schwantes.

Schwantes escreveu pensando nos problemas e no sofrimento que marcaram a realidade de seus dias. Seus escritos enfatizam um Deus do presente: "e há um momento todo especial no qual Javé 'é', 'acontece' e 'age"'78. O acento maior recai sobre a atualidade. A realidade presente encaminha novos rumos proféticos. Ela clama pelo Messias justo e libertador. Em Schwantes, "o Messias não só é pelos pobres, não só constitui sua defesa, Ele mesmo é frágil, é criança, é pobre [...] Nele é enfatizada, de modo insistente e preferencial, a defesa dos empobrecidos" 79 . A teologia do Deus presente e do Messias empobrecido resgata a esperança da presença divina em meios aos novos desafios. Pois, "aquele que vem da miséria da manjedoura e sofre a opressão da cruz é o mais solidário com os doentes, prostitutas, pobres" 80 .

As características do Deus presente e do Messias solidário indicam o agir divino em benefício dos que sofrem. Entretanto, esse discurso por si só não resolve os problemas relacionados, por exemplo, ao desemprego e a fome crescentes no contexto da pandemia. Recorre-se, portanto, ao que Schwantes postulou em relação ao tribalismo no antigo Israel:

O tribalismo visa a ajuda entre os clãs. É uma complementação das necessidades familiares. É uma experiência de complementariedade nas diferenças. Enfim, o tribalismo é um sistema de partilha. Ele representa a organicidade e o dinamismo interno do povo de Deus, em particular, de seus setores campesinos. ${ }^{81}$

Destaca-se aqui a experiência de partilha entre os clãs a partir da organização tribal. A organização é fundamental para viabilizar a sobrevivência. Neste sentido, uma leitura da realidade presente reflete sobre a premência de uma organização social em favor dos que padecem necessidade, sobretudo, os vitimados pela situação do distanciamento físico.

Para Schwantes, "os movimentos populares são vitais tanto como germes da nova sociedade quanto como organizações de luta para a imposição e o avanço dos interesses

78 SCHWANTES, 1988a, p. 10.

79 SCHWANTES, Milton. Esperanças messiânicas e davídicas. Estudos Bíblicos, Petrópolis, v. 23, p. 18-29, 1989b. p. 28.

80 SCHWANTES, 1989b, p. 29.

81 SCHWANTES, 1987a, p. 45.

Protestantismo em Revista | São Leopoldo | v. 46, n. 01 | p. 34-49| Jan./jun. 2020

Disponível em: <http://periodicos.est.edu.br/index.php/nepp> 
populares" 82 . Destarte, na trajetória da transformação, a organização é fundamental. Mas, parece que a realidade presente impõe limites para reunir e agrupar pessoas de maneira organizada. A pergunta é: como reunir e organizar pessoas em tempos de distanciamento físico? Aqui, propõe-se que seja por meio dos espaços religiosos. Schwantes comenta que a estrutura física dos templos é relativamente importante, enquanto instrumentos de serviço. Todavia, o conteúdo da igreja são as pessoas. ${ }^{83}$ Neste sentido, a realidade presente impõe um novo desafio pastoral/social. Propõe as instituições religiosas uma ação-transformadora ${ }^{84}$ para além de seus espaços físicos:

\begin{abstract}
Daí advém outras tarefas para as igrejas. Não estamos habituados à proximidade dos movimentos populares. Por séculos, nossas igrejas se empenharam em outro tipo de prática, justamente autônoma diante das angústias populares, autossuficiente em relação aos clamores dos "porões da humanidade", porque circulavam nas imediações do poder dos senhores como, em boa medida, ainda o fazem. Ora, olhemos para o jeito de ser de nossas organizações eclesiásticas! Teoricamente todos absorvemos, de algum modo, a ideia democrática de que todos os batizados têm acesso às decisões. Junto com o avanço das práticas democráticas, impôs-se também certo democratismo nas igrejas. Mas, esta democracia interna é mui restritiva. ${ }^{85}$
\end{abstract}

A crítica desferida por Schwantes indica que barreiras precisam ser rompidas para que, de fato, as instituições religiosas se organizem em favor dos que sofrem. Sobretudo, as barreiras teológicas. Os processos seletivos, por assim dizer, excluem o povo. Desta forma, a nova leitura bíblica e teologia propostas por Schwantes idealizam uma igreja solidária com a luta do oprimido, do camponês, da mulher, do indígena, etc. Isto é, uma igreja de rosto popular. Enfim, uma atitude de caridade para todos/as aqueles/as que experimentam o sofrimento em suas variadas formas. ${ }^{86}$

Para Schwantes, a "teologia bíblica junto ao povo" é o modelo ideal para esta empreitada, pois "considera como algo elementar que o uso popular da Bíblia dá rosto e dignidade. A experiência bíblica é traduzível em experiência de cidadania. Ao se reapropriar da Escritura, as comunidades dos empobrecidos se reapropriam do seu direito à vida" 87 . A teologia proposta por Schwantes, entretanto, não desloca o valor das coisas terrenas para uma esfera espiritual. Afinal, "não deixamos de ser carne e osso" ${ }^{88}$. Para ele, "a leitura bíblica exercitada nas comunidades populares também é espiritual, e o é de uma maneira muito intensa [...] Nelas a espiritualidade incorpora, explicitamente, o concreto da vida" ${ }^{89}$. Neste sentido, a teologia que se deve resgatar nas igrejas, para lidar com a realidade presente, é eminentemente espiritual, mas de um modo muito encarnado e histórico.

82 SCHWANTES, 1987a, p. 46.

83 SCHWANTES, 1987b, p 180.

84 Ação-transformadora como postula Agenor Brighenti. Para ele, toda a ação, incluída a ação pastoral, é também portadora de uma racionalidade. Isto é, sem ciência, a pastoral deixa de ser uma ação pensada criticamente. BRINGHENTI, Agenor. Ciência da Religião aplicada à ação pastoral. In: PASSOS, João Décio; USARSKI, Frank (Org.). Compêndio de Ciência da Religião. São Paulo: Paulinas; Paulus, 2013. p. 671.

85 SCHWANTES, 1987a, p. 46.

86 SCHWANTES, 1987a, p. 47.

87 SCHWANTES, 1987a, p. 48.

88 SCHWANTES, 1987a, p. 49.

89 SCHWANTES, 1987a, p. 49.

Protestantismo em Revista | São Leopoldo | v. 46, n. 01 | p. 34-49| Jan./jun. 2020

Disponível em: <http://periodicos.est.edu.br/index.php/nepp> 
Esta afirmação pode gerar diversos conflitos e críticas no âmbito das pesquisas acadêmicas. A despeito de conhecê-las, Schwantes não as prioriza. Para ele, essa aproximação da Bíblia à realidade presente,

\begin{abstract}
Não é o que aprendemos na academia! Ela insiste no contrário: a Bíblia está distante! Sua cosmovisão não seria a do "homem moderno". Sua formulação da boa nova estaria irremediavelmente encapada nos limites culturais de seu tempo. Enfim, entre nós e a Bíblia haveria um fosso profundo. [...] Estas e outras vozes críticas, se bem que devam ser levadas muito a sério, via de regra, abordam a Escritura desde uma perspectiva cultural e desde experiências do assim chamado "homem moderno" consumidor. Nossa abordagem não dá prioridade a tais mediações. As comunidades populares sintonizam os conteúdos escriturístico desde uma perspectiva concreta e material e desde uma prática de luta e conflito. A este nível, a Bíblia é um livro presente. [...] é nosso dia a dia. ${ }^{90}$
\end{abstract}

Portanto, a proposta teológica de Schwantes dá primazia à experiência da proximidade da Bíblia em tempos presentes. A Bíblia deve estar presente nos conflitos atuais.

Na primeira seção deste artigo, por meio do depoimento de Carlos Mersters, foi ilustrada uma atitude "profética" de Milton Schwantes, durante o encontro realizado pelo CEBI, em 1983. Este artigo se inscreve nesta perspectiva. A despeito das circunstâncias que impõe um distanciamento físico e não social, uma leitura da realidade presente lança novos desafios teológicos e práticos. Na teologia de Schwantes, Deus age no presente e está com o seu povo. O Messias é pobre e vive com os marginalizados - mulheres, crianças, doentes, famintos e todos/as aqueles/as que experimentam o sofrimento em suas variadas formas - a eles/as é dada a primazia. No entanto, esta teologia tem seu lugar no serviço das instituições religiosas junto aos movimentos populares, enraizada na ação pastoral/social. Da mesma forma, no dia a dia, a Bíblia é uma companhia indispensável. Esta teologia não pode, portanto, ser "queimada e esquecida".

\title{
Considerações finais
}

Convém ressaltar que o tema é amplo e complexo e envolve questões sérias que o artigo não aborda. Faz-se necessário um acompanhamento dos debates em torno da temática e avaliar outros posicionamentos. É preciso também considerar a novidade dos acontecimentos - ainda não se tem uma previsão do fim do distanciamento físico - tudo é muito recente e as respostas permanecem incognitivas. Cabe, portanto, apontar caminhos possíveis para uma reflexão teológica que enfatize o valor da vida e proponha uma práxis transformadora.

São inegáveis as contribuições de Milton Schwantes para a comunidade teológica e os setores populares. No Brasil, na América Latina e no mundo, este exímio autor é reconhecido por seu jeito peculiar de ler e interpretar a Bíblia. A despeito de seu falecimento, em 2012, suas contribuições não foram "queimadas e esquecidas". Ao contrário, seus escritos evidenciam que o conteúdo de sua teologia permanece atual, relevante e indispensável. Desta forma, este artigo buscou resgatar os elementos de mediação pastoral/social que perpassam as obras do autor.

90 SCHWANTES, 1987a, p. 49-50.

Protestantismo em Revista | São Leopoldo | v. 46, n. 01 | p. 34-49| Jan./jun. 2020

Disponível em: <http://periodicos.est.edu.br/index.php/nepp> 
A realidade presente solicita por uma leitura bíblica e reflexão teológica capazes de situar o sentido do texto bíblico no aqui e agora. Uma leitura que não desconfigure as imagens de Deus e do Messias, isto é, que não os interprete como agentes do caos e da destruição do mundo, por causa do pecado da humanidade. Por conseguinte, os projetos teológicos de Schwantes apresentam-se como relevantes e indispensáveis para propor caminhos possíveis diante dos novos desafios que surgem. Na prática, Schwantes representa a junção perfeita entre reflexão teórica e ação-transformadora. Isto é, uma ação pastoral/social portadora de uma racionalidade e passível de reflexão crítica.

Uma leitura da realidade presente, sob a ótica de Milton Schwantes, também impõe outros compromissos. Pois, ele produziu uma teologia que enfatiza o valor da vida e posteridade, desafia as instituições religiosas a uma ação pastoral/social junto aos movimentos populares e reivindica que as relações sociais se enriqueçam na partilha, na complementariedade, na luta pela vida e cidadania.

O desafio é lançado para todas as instituições religiosas independentemente de suas crenças e práticas. A palavra "igreja" aparece algumas vezes no corpo do artigo, sobretudo, nas citações diretas. Pois, Schwantes foi cristão e pastor luterano, por isso, ele fala a partir de suas experiências. No entanto, seu perfil é profundamente ecumênico. É preciso considerar que leitura bíblica e Milton Schwantes, numa perspectiva acadêmica, são termos indissociáveis.

Por esta razão, se "tudo que fizermos com a Bíblia para a formação: pesquisa, estudo, línguas, cursos, projetos, aprofundamento, comentários, se não estiver a serviços dos grupos de base, onde a palavra de Deus entra na vida [...] que seja queimado e esquecido".

\section{Referências}

BARROS, Marcelo. Salmo das travessias - conversa com Milton Schwantes sobre o salmo 121. Estudos Bíblicos, Petrópolis, v. 29, n. 114, p. 19-26, 2012.

BERGER, Peter L. O dossel sagrado: elementos para uma teoria sociológica da religião. São Paulo: Paulinas, 1985.

BRINGHENTI, Agenor. Ciência da Religião aplicada à ação pastoral. In: PASSOS, João Décio; USARSKI, Frank (Orgs.). Compêndio de Ciência da Religião. São Paulo: Paulinas; Paulus, 2013. p. 663-673.

CASTELLS, Manuel. A sociedade em rede. São Paulo: Paz e Terra, 2005.

CROATTO, José Severino. Hermenêutica bíblica: para uma teoria da leitura como produção de significado. São Leopoldo: Sinodal; São Paulo: Paulinas, 1986.

DREHER, C. A. Milton Schwantes: um perfil biográfico. In: DREHER, C. A. et al (Orgs.). Profecia e Esperança: um tributo a Milton Schwantes. São Leopoldo: Oikos, 2006. p. 11-23.

DREHER, C. A.; MUGGE, E.; HAUENSTEIN, I.; DREHER, I. R. (Orgs.) Profecia e Esperança: um tributo a Milton Schwantes. São Leopoldo: Oikos, 2006.

KAEFER, José Ademar. A estela de Dã. Caminhando, São Bernardo do Campo, v. 17, n. 2, p. 3346, 2012.

Protestantismo em Revista | São Leopoldo | v. 46, n. 01 | p. 34-49| Jan./jun. 2020

Disponível em: <http://periodicos.est.edu.br/index.php/nepp> 
MERSTERS, Carlos. Milton, nosso mestre. In: PEREIRA, Nancy Cardoso (Org.). Milton Schwantes: escritos de história e paixão. São Leopoldo: CEBI, 2012. p. 7-11.

MINISTÉRIO DA SAÚDE. Sobre a doença. Disponível em: <https://coronavirus.saude.gov. br/sobre-a-doenca\#o-que-e-covid>. Acesso em 17 abr. 2020.

REIMER, Ivoni Richter; REIMER, Haroldo. Misericórdia quero! Uma ética do cuidado a partir das entranhas. Estudos Bíblicos, Petrópolis, v. 29, n. 114, p. 27-37, 2012.

RIBEIRO, Cláudio de Oliveira. "O olhar de quem sabe amar": aspectos da teologia ecumênica e sociopolítica de Milton Schwantes. Caminhando, São Bernardo do Campo, v. 17, n. 2, p. 95 106, 2012.

SANTOS, Suely Xavier. Milton Schwantes: a messianidade vai tomando forma de cruz! Caminhando, São Bernardo do Campo, v. 17, n. 2, p. 47-54, 2012.

SCHWANTES, Milton. Interpretação de Gn 12-25, no contexto da elaboração de uma hermenêutica do Pentateuco. Estudos Bíblicos, Petrópolis, p. 31-49, 1984a.

. "Da boca dos pequeninos..." - enfoques antropológicos. Estudos Teológicos, São Leopoldo, ano 24, n. 2, p. 148-160, 1984b.

. Bíblia e Lutero. Caminhando, ano 2, v. 2, p. 32-34, 1984c.

Teologia Bíblica junto ao povo - anotações preliminares. Estudos de Religião, São Bernardo do Campo, n. 3, p. 43-56, 1987a. $180,1987 b$

. A herança de Javé - meditando o Salmo 127. Estudos Teológicos, ano 27, n. 2, p. 17529-30, 1989a.

Toda criação geme e suporta angústias. Tempo e Presença, Rio de Janeiro, n. 246, p.

. Esperanças messiânicas e davídicas. Estudos Bíblicos, Petrópolis, v. 23, p. 18-29, 1989b.

Caminhos da teologia bíblica. Estudos Bíblicos, Petrópolis, n. 24, p. 9-19, 1989c.

- Natã precisa de Davi - na esperança da igreja profética. Estudos Teológicos, São Leopoldo, ano 18, n. 3, p. 99-118, 1978.

. O direito dos pobres. São Leopoldo: Oikos; São Bernardo do Campo: Editeo, 2013.

. O êxodo como evento exemplar. Estudos Bíblicos, Petrópolis, v. 16, p. 9-18, 1988a.

. Jacó é pequeno - visões em Amós 7-9. Revista de Interpretação Bíblica LatinoAmericana, Petrópolis, v. 1, n. 2, p. 81-92, 1988b.

. Javé abrigou: anotações teológicas à luz do livro de Sofonias. Estudos de Religião, São Bernardo do Campo, n. 13, p. 25-44, 1997.

. "Não estendas tua mão contra o menino" (Observações sobre Genesis 21 e 22). Revista de Interpretação Bíblica Latino-Americana, Petrópolis, v. 10, p. 24-39, 1991.

. Plantarei o meu povo na terra que Ihes dei. Revista Eclesiástica Brasileira (REB), Petrópolis, v. 52, fasc. 206, p. 424-428, 1992.

Protestantismo em Revista | São Leopoldo | v. 46, n. 01 | p. 34-49| Jan./jun. 2020

Disponível em: <http://periodicos.est.edu.br/index.php/nepp> 
Profecia e organização - Anotações à luz de um texto (Am 2,6-16). Estudos Bíblicos, Petrópolis, n. 5, p. 26-39, 1985.

SIQUEIRA, Tércio Machado. A Torá: uma leitura inovadora. Caminhando, Petrópolis, v. 17, n. 2, p. 21-31, 2012.

WITT, Hans de. "It Should Be Burned And Forgotten!" Latin American Liberation Hermeneutics through the Eyes of Another. In: BOTTA, Alejandro F.; ANDIÑACH, Pablo R. The Bible and the Hermeneutics of Liberation. Atlanta: Society of Biblical Literature, 2009. p. 39-60.

WIT, Hans de. En la dispersión el texto es patria: introducción a la hermenéutica clásica, moderna e pós-moderna. San José (Costa Rica): Universidad Bíblica Latino Americana, 2002. 